\title{
VILLAS MISERIA, FAVELAS Y ASENTAMIENTOS: \\ NUEVAS RUTAS EN HISTORIA URBANA
}

\section{SHANTY TOWNS AND INFORMAL SETTLEMENTS: NEW DIRECTIONS IN URBAN HISTORY}

v. 9, n. 1 [15]

jan/abr (2017)

Editorial

\author{
Prof $^{\text {a }}$ Dra Rosa Aboy $^{\text {a }}$ \\ Universidad de Buenos Aires \\ rosaboy@gmail.com
}

En años recientes ha crecido el interés académico hacia las urbanizaciones conocidas como villas miseria, favelas, cantegriles, callampas y asentamientos, como objeto de estudio, dando como resultado un importante corpus de trabajos científicos enfocados principalmente en su composición social, en las experiencias de organización de sus habitantes, en los conflictos sociales y políticos, y en las políticas públicas implementadas. ${ }^{1}$ Los trabajos provenientes de la sociología, la antropología, la historia reciente y la ciencia política, que tienen en estos sectores de ciudad su objeto de estudio, permiten acceder al conocimiento de las cambiantes situaciones y a los conflictos de índole económica y política que atraviesan su tejido social, así como a las tensiones entre sus habitantes y la urdimbre urbana, más amplia, en que se insertan. A pesar de la importancia cualitativa y cuantitativa de estas urbanizaciones dentro del tejido urbano de ciudades como Buenos Aires, San Pablo, México, Salvador, Santiago, Montevideo, o Rio, los

\footnotetext{
${ }^{1}$ En los diferentes países latinoamericanos, se designa como villas miseria, favelas, cantegriles o callampas, entre otras denominaciones, a las urbanizaciones no planificadas en tierra vacante, por parte de familias e individuos, a lo largo del tiempo. Coincidimos con la mirada de Cravino, quien las entiende como urbanizaciones, con vocación de integración al resto de la ciudad. M. C. Cravino, Entre el arraigo y el desalojo. La Villa 31 de Retiro. Derecho a la ciudad, capital inmobiliario y gestión urbana, Buenos Aires: Universidad Nacional de General Sarmiento y Vivir en la villa. Relatos, trayectorias y estrategias habitacionales, Buenos Aires: Universidad Nacional de General Sarmiento, ambos de 2009. En el contexto de este artículo, se utilizan las expresiones "urbanizaciones irregulares" en referencia a su trama, por oposición a las ciudades regulares de tradición hispánica y, en algunos casos "urbanizaciones informales", por materializarse por fuera del mercado formal de la vivienda. Ambas expresiones se utilizan, de manera indistinta, a lo largo del artículo.
} 
historiadores urbanos hemos dedicado a ellas menor atención que, por ejemplo, a la vivienda de ayuda estatal, al habitar de los sectores medios o a las casas y departamentos de las elites.

Este Dossier reúne una serie de investigaciones sobre este tipo de urbanizaciones, materializadas en tierras vacantes, principalmente tierras fiscales, que se caracterizan por formar tramas urbanas irregulares, con unidades habitacionales relativamente precarias, ausencia de algunos servicios e infraestructura pública, y con alta densidad habitacional. Estas urbanizaciones se han consolidado como la forma de habitar de los sectores sociales más humildes, en las ciudades latinoamericanas, desde la segunda mitad del siglo XX, si bien su emergencia puede datarse con anterioridad. Estas investigaciones cubren un área de vacancia temática, esencial para la comprensión de las dinámicas sociales, la construcción de identidades y las formas de habitar en las grandes urbes latinoamericanas. Sus autores asumen que la perspectiva histórica es fundamental para comprender el universo simbólico del presente de las villas y sus circunstancias. Por su parte, y consecuentemente, la mirada histórica constituye una herramienta de análisis ineludible para la articulación de respuestas a las problemáticas actuales, que contemplan la inclusión de prácticas de planeamiento participativo y políticas de urbanización que toman distancia discursiva, y muchas veces también fáctica, de las políticas preexistentes, tendientes en buena medida a la erradicación y traslado compulsivo de sus habitantes, cuando no a la simple y llana invisibilización de las mismas.

En cuanto al recorte temporal, se ha optado por cierta elasticidad, puesto que la aparición de estas urbanizaciones tuvo diferentes temporalidades, de acuerdo a las dinámicas asumidas en los diferentes países del continente. La consolidación de esta forma de habitar estuvo ligada a los procesos de concentración urbana, derivados de la modificación en los términos de intercambio, las políticas de fomento a la industrialización, vinculadas a ideas keynessianas, y la migración de trabajadores rurales hacia las ciudades. Si bien la aparición de las primeras urbanizaciones irregulares puede datarse desde fines del siglo XIX, fue para mediados del siglo XX que asumieron dimensiones hasta entonces inéditas. Fue entonces, cuando los modelos de desarrollo económico en la región promovieron la modernización de la sociedad, que pasaría de rural a urbana e industrial, con las consecuente modificación del empleo. Este modelo de desarrollo trajo aparejados problemas de distribución, a la par de cierto crecimiento económico. ${ }^{2}$

Desde el punto de vista urbano también hubo inconvenientes, pues la concentración poblacional en las ciudades latinoamericanas no siempre fue de la mano de un mejoramiento sustancial de las condiciones de vida de los sectores populares. Si bien un importante número de personas llegadas a las ciudades en busca de empleo logró acceder al mercado de trabajo,

2 Sobre la emergencia de este tipo de urbanizaciones, véase la Tesis de Doctorado en Historia de Valeria Snitcofsky, 'Villas de Buenos Aires: historia, experiencia y prácticas reivindicativas de sus habitantes (1958-1983)". Universidad de Buenos Aires, 2015. 
no todos tuvieron garantizado el acceso a la vivienda, puesto que ni el mercado privado, ni tampoco el Estado, habían acompañado el ritmo de los cambios con la provisión de las viviendas necesarias. Este proceso tuvo diferentes temporalidades, de acuerdo a las dinámicas asumidas en cada uno de los países. En los casos de Brasil y de la Argentina, por ejemplo, hubo activas políticas de creación de vivienda estatal, en los años del varguismo y del peronismo, que fueron decisivos y dejaron una impronta insoslayable en las identidades sociales y políticas. ${ }^{3}$

Sobre todo en el caso argentino, la acción del gobierno de Juan Perón en la materia, cristalizó en identidades políticas que posteriormente tendrían impronta en las experiencias de lucha y reivindicación de los habitantes de las villas miseria frente a los intentos de erradicación de las sucesivas dictaduras, cuando los representantes de los habitantes de las urbanizaciones estuvieron en buena medida, identificados con la militancia peronista. Algunos de los trabajos reunidos en este Dossier arrojan nueva luz sobre estos temas y revisitan las experiencias asociativas y de resistencia, y sus vinculaciones con las identidades políticas de representados y representantes.

Como ha mostrado la bibliografía, las estrategias de la población que no pudo acceder a las viviendas de ayuda estatal, se inclinaron, por un lado, a alquilar habitaciones en viviendas urbanas compartidas, la mayoría de las veces en condiciones materiales deficitarias y con hacinamiento individual y colectivo. En otros casos, para quienes accedían a empleos informales, consecuentemente peor remunerados, o quienes quedaban fuera del mercado laboral, la opción fue encontrar un espacio para construir un refugio en tierras vacantes y en los márgenes de las ciudades. De acuerdo a factores como la cultura urbana, la gestión y valorización de la tierra y las características topográficas de las diferentes ciudades latinoamericanas, esas localizaciones variaron: en el alto o en tierras bajas e inundables, cerca de cursos de agua o en las colinas que rodeaban la ciudad consolidada, en tierras fiscales cercanas a los ferrocarriles, etcétera. Estos primeros asentamientos fueron entendidos inicialmente, por parte de distintos gobiernos, como un problema pasajero, que sería resuelto con el proceso de crecimiento económico y a través de las dinámicas de ascenso social.

Por su parte, la mirada higienista, que había construido discursos disciplinadores y alentado la sanción de leyes que afectaron la vivienda de los sectores más pobres (conventillos, casas de vecindad e inquilinatos) y a sus habitantes, en los diversos países latinoamericanos en el siglo XIX y las primeras décadas del siguiente, ${ }^{4}$ pervivió, a veces de manera sutil, a lo largo

3 Para el caso brasilero, véase N. Bonduki, Origens da habitacao social no Brasil, San Pablo: Estacao Liberdade, 2011 y Ana Paula Koury y N. Bonduki, Os pioneiros da habitacao social. Cem anos de política pública no Brasil, San Pablo: UNESP, 2012. Para el argentino, véase A. Ballent, Las huellas de la política. Vivienda, ciudad, peronismo en Buenos. Aires, 1943-1955. Buenos Aires: Universidad de Quilmes, 2005 y R. Aboy, Viviendas para el Pueblo. Espacio urbano y sociabilidad en el Barrio Los Perales, $1946-1955$. Buenos Aires: Fondo de Cultura Económica- UdeSA, 2005, entre otros.

${ }^{4}$ Al respecto véase David S. Parker \& Gabriela Castillo, "Laws in Translation: Asymmetric Globality and the Dialogue between French Expert Knowledge and Chilean Social Legislation, 1889-1931", Queen's University, 2017 (Inédito) 
del siglo XX. Para las décadas de 1950 y 1960, las reverberaciones del discurso higienista de las elites latinoamericanas fueron activadas al calor de los procesos de urbanización acelerada y se fusionaron con un conjunto de valores, ligados a la modernización cultural.

Para entonces, comenzaron a identificarse las deficitarias características de las viviendas de los pobres, con las costumbres rurales de sus pobladores, que no habrían asimilado aún, unas supuestas "pautas culturales modernas". Esta modernidad cultural iba de la mano de un nuevo estilo de vida urbana, asentado en la familia nuclear, ${ }^{5}$ en contraposición a la familia extendida, característica del medio rural. Los valores del modelo familiar nuclear estaban ligados a la propiedad de la vivienda, la planificación de la natalidad y el ascenso social a través del esfuerzo y la educación. El modelo incorporaba una valorización del confort a través del consumo de objetos durables provistos por los sectores industriales y promovidos por la prensa, la publicidad, el cine, las revistas y el mercado de la moda, crecientemente masificado. ${ }^{6}$

Una creciente estigmatización de las pautas culturales de los habitantes de las urbanizaciones y de sus prácticas de domesticidad, se consolidó a la par del proceso de industrialización en América Latina, que entre las décadas de 1940 y 1960 intensificó las dinámicas de concentración urbana. Estos procesos agudizaron la crisis de vivienda, puesto que el stock habitacional no crecía en la medida de las necesidades de la población. En este contexto, las villas miseria, favelas, callampas, cantegriles y asentamientos aumentaron su extensión y número de habitantes, mientras los gobiernos civiles y militares, que se alternaban en el continente, ensayaron diferentes respuestas que, miradas en conjunto, no lograron dar solución al déficit habitacional ni tampoco a los problemas sociales, políticos y ambientales de las urbanizaciones.

No deja de ser paradójico, que en años en que el ideal modernizador en torno de la familia nuclear (identificada como un núcleo familiar primario habitando una unidad residencial para su exclusivo uso) había impregnado los discursos y en general, las representaciones sobre la familia, algunas investigaciones sobre importantes capitales latinoamericanas, por ejemplo, la ciudad de Buenos Aires, muestren la pervivencia de la práctica de compartir viviendas entre varios núcleos familiares. En efecto, el análisis de la información censal para la capital argentina puso en evidencia que para 1960 las viviendas de la ciudad fueron compartidas entre un mayor número de personas que en la medición anterior, el Censo de 1947. En 1960, el promedio de personas por vivienda se incrementó en un $12 \%$, sobre la totalidad de las viviendas de la ciudad y en un contexto en el cual el tamaño promedio de las familias había descendido de 3.80 a 3.14

5 Sobre la instauración del modelo de la familia nuclear, E. Míguez, "Familias de clase media: la formación de un modelo". En Devoto, F y Madero, M. Historia de la vida privada en Argentina. La Argentina plural (1870-1930). Buenos Aires. Taurus, 1999. También I. Cosse, Pareja, sexualidad y familia en los años sesenta: una revolución discreta. Buenos Aires. Siglo XXI, 2010.

${ }^{6} \mathrm{Al}$ respecto, véase R. Fernández Wagner, "La construcción y deconstrucción histórica de lo social en el acceso a los bienes y servicios del hábitat". En Boletín del Instituto de la Vivienda. Mayo, Vol. 10, Núm. 50, Universidad de Chile, Santiago de Chile, 2004. 
miembros. ${ }^{7}$ En síntesis, las familias eran más pequeñas, pero las viviendas eran compartidas por un mayor número de núcleos familiares bajo el mismo techo.

Desde principios de la década de 1960, la presencia de las urbanizaciones irregulares, y de sus habitantes, en la escena urbana, comenzó a ser objeto de reflexión por parte de las ciencias sociales. Al tiempo que en los círculos académicos se comenzó a hablar de las "urbanizaciones de la pobreza", su aumento comenzó a llamar la atención de los diversos estados latinoamericanos, que desde fines de la década de 1950 y en la década siguiente, las percibieron como un "desorden urbano". ${ }^{8}$ En contextos políticos autoritarios, estas urbanizaciones fueron asimiladas a un mal descontrolado y consecuentemente, las políticas diseñadas para lidiar con este problema consistieron, lisa y llanamente, en extirpar el problema del cuerpo social. Esta mirada reforzó las barreras sociales y culturales preexistentes, y de larga data, entre las urbanizaciones y la "ciudad moderna", que se veía a sí misma escindida de las primeras. ${ }^{9}$ De este modo, se operó la transición, desde la invisibilización inicial, hacia un consenso social en torno a las políticas que, en un extremo, consistieron en arrasar los asentamientos, erradicar a sus ocupantes, y llevarlos a vivir a nuevas viviendas, construidas por lo general lejos del sitio original. Estas nuevas viviendas debían ser, ineludiblemente, "modernas".

El requisito de modernidad implicaba que las nuevas viviendas fuesen concebidas como verdaderos laboratorios sociales, en los cuales los individuos y las familias operaran la transición desde sus pautas culturales de origen hacia un horizonte considerado como "civilizador". Paralelamente, desde el campo intelectual, se estaban alumbrando las perspectivas fundacionales sobre las urbanizaciones informales. En este Dossier se discuten algunos de esos enfoques tradicionales. Para el caso de la composición social de las villas miseria en la Argentina, se revisitan las hipótesis de Gino Germani y de José Luis Romero, que abordaron la cuestión desde la sociología y desde la historia, respectivamente. ${ }^{10}$ Ambos enfoques, habían asociado la conformación de las urbanizaciones en Buenos Aires con la etapa de desarrollo industrial y con las transformaciones acaecidas durante los primeros gobiernos peronistas. Las nociones de desintegracion social de Germani y de anomia, de Romero, son revisitadas para marcar su pervivencia en la bibliografía posterior, en la cual habrían colaborado a demarcar y reforzar las fronteras sociales preexistentes, entre los habitantes de estas urbanizaciones y el resto de la ciudad.

7 Este análisis en R. Aboy, "Arquitecturas de la vida doméstica. Familia y vivienda en Buenos Aires, 19141960". Anuario IEHS, número 23, pp. 355- 384. ISSN 0326-9671. Tandil, 2008

8 He tomado la noción de "desorden urbano" de Fernández Wagner, ob.cit.

9 Sobre la noción de "frontera social", véase mi artículo "Ellos y nosotros. Fronteras sociales en los años del primer peronismo". En Nuevo Mundo Mundos Nuevos, Revista electrónica editada por L'Ecole des Hautes Etudes en Sciences Sociales. Marzo, N. , ISSN 1626-0252. 2008.

$10 \mathrm{G}$. Germani, "Investigación sobre los efectos sociales de la urbanización en un área obrera del Gran Buenos Aires", en Hauser, Philipe (editor), La urbanización en América Latina, Buenos Aires: Unesco, 1961; Política y sociedad en una época de transición. De la sociedad tradicional a la sociedad de masas. Buenos Aires: Paidós, 1962. J. L. Romero, Latinoamérica, las ciudades y las ideas. Buenos Aires: Siglo XXI, 1976. 
A lo largo de la vida de las urbanizaciones informales, en estos sectores de ciudad se produjeron transformaciones históricas que afectaron a su demografía, su organización social y la participación política y sindical de los sectores de trabajadores y desocupados que los habitaron. Estos ciudadanos, si bien carecieron de los recursos económicos para acceder al mercado formal de la vivienda, pudieron, en muchos casos, dar visibilidad a sus reclamos y negociarlos con los poderes públicos. En determinados países y escenarios históricos, los habitantes de las urbanizaciones irregulares vieron ampliados sus derechos y posibilidades de acceso a mejorar su calidad de vida, accediendo a nuevos consumos materiales y simbólicos.

Estos avances y conquistas se vieron brutalmente cercenados en otras coyunturas históricas, siendo las dictaduras militares quienes elaboraron las políticas más agresivas y violentas hacia estas urbanizaciones y sus habitantes. Sin embargo, sería una simplificación aplicar de manera taxativa una lectura sin mediaciones que identifique la democracia con un avance en los derechos de los habitantes de las urbanizaciones informales y la dictadura con la represión de los mismos. Las investigaciones recientes muestran un panorama mucho más poroso, que contradice lecturas más binarias y sin duda, más tranquilizadoras.

Algunas experiencias pioneras de proyectos participativos de vivienda de ayuda estatal, orientadas a mejorar las condiciones de vida de las urbanizaciones a través de "asociaciones para el proyecto y la ayuda mutua en la autoconstrucción" de viviendas, no tuvieron lugar bajo gobiernos democráticos. Por ejemplo, en el caso de la Villa 7 en Buenos Aires, la experiencia tuvo lugar durante el tercer ciclo de la dictadura conocida como Revolución Argentina, bajo el gobierno de facto del General Lanusse. ${ }^{11}$ Se trató de un proyecto elaborado y ejecutado en conjunto entre los técnicos de la Comisión Municipal de la Vivienda y los habitantes de las futuras unidades habitacionales que habrían de reemplazar al asentamiento del que provenían, trasladando el barrio a un terreno lindero. Esta experiencia puede considerarse modélica desde el punto de vista socio- urbano. Debido al éxito en la ejecución, adjudicación y posterior apropiación de las viviendas, el caso de Villa 7 fue reconocido y tomado como ejemplo para muchas experiencias cooperativas posteriores, algunas de las cuales son analizadas en los artículos que integran este Dossier.

Ahora bien, si algunas de las experiencias más innovadoras no tuvieron lugar bajo gobiernos democráticamente elegidos, no es menos perturbador que algunos de los más violentos hechos represivos de las reivindicaciones sociales y políticas de los habitantes de las urbanizaciones informales y de sus referentes, hayan acaecido en ellos. Como ejemplo paradigmático de lo segundo, cabe citar los asesinatos del cura Carlos Mugica, referente del

11 Ver al respecto, R. Barrios, El Plan de Realojamiento de la Villa 7 en Mataderos, en Ciudad de Buenos Aires, entre 1971 y 1975 . Tesis de Maestría en Administración Pública. Buenos Aires: Facultad de Ciencias Económicas, Universidad de Buenos Aires, 2012. Tambien de la autora, "Entre la incapacidad de acción y la autonomía. Miradas sobre la participación popular en políticas de vivienda y hábitat en las décadas del 60 y 70 en argentina. Los aportes de John Turner y Víctor Pelli". Cuaderno Urbano núm. 16; junio 2014. issn 1853 - 3655 
Movimiento de Sacerdotes para el Tercer Mundo ${ }^{12}$, y activo representante de los derechos de los villeros ante la jerarquía eclesiástica, el 11 de mayo de 1974, en Buenos Aires y el de Alberto Chejolán, emblemático representante de la Villa 31 de Retiro, el 25 de marzo de 1974. Ambos fueron asesinados por miembros de la banda paraestatal conocida como Triple $A$, durante el tercer gobierno peronista. El líder de esta organización, el entonces Ministro José López Rega, fue un precursor a la hora de sentar los lineamientos de lo que posteriormente fue el accionar de la última dictadura militar argentina, en relación con las urbanizaciones.

La dictadura inaugurada en Argentina en marzo de 1976 llevó a cabo uno de los planes de erradicación más violentos de la historia de las ciudades latinoamericanas ${ }^{13}$. En ese período, se demolió la mayor parte de la estructura urbana y habitacional de las villas y simultáneamente, se desmantelaron las organizaciones, asesinando y "desapareciendo" a muchos de sus referentes políticos. ${ }^{14}$ La aplicación del Plan de Erradicación buscó expulsar de la ciudad a la totalidad de los habitantes de las villas hacia tierras de menor valor económico en los suburbios, haciendo uso de la violencia estatal. El resultado fue que mientras para 1976 la población total de las villas era de 213.823 personas, en 1980 había descendido a $34.068 .{ }^{15}$ En el caso de la última dictadura argentina, que gobernó hasta 1983, se percibe un alto grado de cohesión entre los discursos y las prácticas estatales en torno a las urbanizaciones informales, que quedaron diezmadas y desarticuladas en su representación y capacidad organizativa.

Los casos señalados en los párrafos precedentes, que dieron como resultado los aparentes desfasajes entre los tiempos de la política, los modelos estatales y las acciones del poder político hacia las urbanizaciones informales no resultan de fácil interpretación. Intuimos determinaciones múltiples detrás de ellos. No es intención de este artículo hacer un análisis concluyente de estos fenómenos, en todo caso, nos limitamos a señalar que en el análisis de las políticas habitacionales es importante estar advertido acerca de buscar correspondencias directas entre los tiempos cortos de la política y los tiempos largos de la vida de las ciudades y de los cambios urbanos, que muchas veces obedecen a lógicas diferentes. Por los tiempos que conlleva la materialización de los cambios en el plano material de la ciudad (tiempos de proyecto,

\footnotetext{
12 Este grupo de sacerdotes realizaba su tarea pastoral en las villas de la Ciudad de Buenos Aires en diálogo con las ideas de la Teología de la Liberación. Se había organizado en medio del clima postconciliar y proponía transformar a las villas en barrios obreros, en tanto éstas no eran consideradas como un hábitat digno. La denuncia de la estigmatización de los villeros y la tarea de los religiosos en su representación no implicaba la defensa de la existencia de urbanizaciones informales. Los curas eran proclives a su relocalización, siempre y cuando fuera llevada a cabo con el consenso de los habitantes y hacia "viviendas dignas". L. Daich Varela, "El barrio La Asunción, relocalización de villas y autoconstrucción cooperativa en el ex municipio de General Sarmiento". Tesis de Doctorado en curso

13 El Plan de Erradicación de Villas (PEVE) había sido inaugurado por el General Onganía, quien fue presidente de facto entre 1966 y 1970.

${ }^{14}$ E. Blaustein, Prohibido vivir aquí: la erradicación de villas durante la dictadura. Buenos Aires: Punto de Encuentro, 2006.

15 L. Daich Varela, ob. cit. Y también L. Daich Varela, "Demandantes, autoconstructores y técnicos. Formas de resistencia en las villas de la Ciudad de Buenos Aires frente a las erradicaciones de la última dictadura militar". Quid 16 N6, 88-120. 2016; "Imágenes de la Cooperativa Copacabana. Un análisis sobre la erradicación de villas y la construcción de viviendas durante la última dictadura a partir de sus fotografías". Clepsidra. Revista Interdisciplinaria de Estudios sobre Memoria No9, (en prensa).
} 
de aprobaciones de acuerdo a leyes y normas, tiempos de construcción, de adjudicación, etcétera), sucede que muchas veces, las iniciativas que tienen inicio en un contexto político determinado, son finalizadas y salen a la luz en circunstancias históricas diferentes, e inclusive antagónicas, respecto del momento inicial.

En segundo lugar, los tiempos de circulación de las ideas en los estratos intelectuales y en las elites profesionales, y su penetración en la cultura de la burocracia estatal, tampoco obedecen de manera lineal a los tiempos de la política, pues fluyen por otros carriles. Para iluminar este aspecto puede citarse la circulación, apropiación y posterior materialización de las ideas de la modernidad arquitectónica, para la vivienda de los trabajadores, en contextos económicos y políticos conservadores e inclusive, antimodernos. Ejemplo de esto son los conjuntos habitacionales de gran escala, construidos en la periferia de las grandes ciudades según ideales sociales y pautas de habitar modernas, en estilo internacional, en época de dictaduras nacionalistas y conservadoras desde el punto de vista social y cultural.

Otro ejemplo son los debates y la aplicación de las ideas de John Turner, quien fue uno de los principales críticos de las políticas de erradicación y promovió la autogestión y la autoconstrucción, a partir de su estudio de las urbanizaciones en Perú, Estados Unidos y el Reino Unido. Sus investigaciones de fines de la década de 1960 concluían que la planificación y los marcos de acción estatal habían sido insuficientes ante la crisis habitacional y proponía solucionar el problema tomando en consideración las estrategias de los sectores populares, en lugar de arrasar con ellas. En este sentido, Turner ponía de manifiesto las habilidades de los habitantes de las urbanizaciones informales para construir sus viviendas e intervenir sobre el hábitat, a pesar de contar con escaso capital económico. ${ }^{16}$ Estas ideas, entroncadas con el pensamiento marxista e ideales autogestivos, impregnaron algunos programas de vivienda elaborados bajo gobiernos dictatoriales.

Las teorías de Turner fueron extensamente discutidas durante la década de 1970 en América Latina, especialmente su obra Vivienda, todo el poder para los usuarios, de 1976, así como los debates con sus críticos, Emilio Pradilla y Rod Burguess, que objetaban a Turner adjudicar capacidades y agencia a los sectores populares, relevando de esa responsabilidad al estado. Estos debates impregnaron el clima intelectual de los profesionales y técnicos que, en esos años, estaban elaborando políticas habitacionales en concordancia con las ideas de autoconstrucción y autogestión del hábitat popular.

Al calor de estas ideas, se gestaron intervenciones que pueden definirse como "soluciones alternativas" para el problema habitacional bajo distintos modelos estatales, en los cuales cierta porosidad permitió la coexistencia de ideas diversas, contenidas bajo el paraguas de idearios laxos de desarrollo y modernización, hallables incluso en gobiernos dictatoriales y de

16 Sobre estos temas, ver R. Barrios, "Entre la incapacidad de acción y la autonomía. Miradas sobre la participación popular en políticas de vivienda y hábitat en las décadas del 60 y 70 en Argentina. Los aportes de John Turner y Víctor Pelli". Cuaderno Urbano 16; Junio 2014. ISSN 1666- 6186 
sesgo cultural conservador. Esta diversidad permitió que al tiempo que los estados erradicaban pobladores de las urbanizaciones informales y los trasladaban a viviendas transitorias $o$ a grandes conjuntos habitacionales en la periferia de las ciudades, paralelamente, tuvieran lugar procesos de autoconstrucción, en los cuales los habitantes transformaban sus barrios, proveyéndose de servicios e infraestructura. Algunos de los trabajos reunidos en este Dossier enfocan este tipo de experiencias.

En la década de 1970 convivieron, entonces, programas de erradicación, que en aras del acceso a "viviendas dignas" acordaban en la necesidad de desmantelamiento de las urbanizaciones informales, a la vez que iban ganando terreno las ideas proclives al mejoramiento de las condiciones habitacionales de las villas, cantegriles, favelas y callampas, en la convicción de que "las razones del fracaso de la acción habitacional corriente - de programas y proyectos para reemplazar moradas deficientes- radicaban en la falta de concordancia entre las necesidades de la gente y las viviendas proporcionadas por las instituciones". ${ }^{17}$ Estas ideas fueron posteriormente recogidas desde agencias internacionales, como la Organización de Estados Americanos, que promovieron mayoritariamente la participación activa de los habitantes en la construcción. La Primera Conferencia sobre los Asentamientos Humanos de Naciones Unidas Hábitat I, realizada en Vancouver en 1976, hizo fuertes recomendaciones en este sentido. ${ }^{18}$

Mientras que desde algunos espacios de gobierno se defendía la intervención del estado frente a sujetos que eran concebidos como portadores de una "incapacidad" para su integración exitosa al escenario urbano, otra corriente de ideas encontró que la provisión de viviendas por el estado, en la matriz de los estados europeos, cuyo ejemplo modélico era la vivienda social construida en la República de Weimar, y que había conocido experiencias exitosas en las ciudades latinoamericanas, era insuficiente para dar respuesta a la demanda del momento. En este sentido, en un contexto de urbanización creciente, la provisión de vivienda repetitiva, planificada por el estado, para familias e individuos estandarizados, dejó de ser vista como la solución para cubrir el déficit. En ese escenario, la mirada que tomaba en consideración algún grado de participación de la población en la solución a su problema habitacional fue ganando terreno.

Los trabajos reunidos en este Dossier, dan cuenta, en buena medida, de la compleja y cambiante interacción entre urbanizaciones informales y estado. En algunos casos, se enfoca el momento en que se conformaron las primeras organizaciones sectoriales a través de las cuales los habitantes eligieron una representación que en muchos casos fue su respuesta frente a las decisiones del poder político de erradicarlas. Los trabajos dan cuenta de la resiliencia de la

17 J. Turner, Libertad para construir. Mexico: Siglo XXI Editores, 1972, p. 177

18 R. Barrios analiza este tema en su artículo "Entre la incapacidad de acción y la autonomía. Miradas sobre la participación popular en políticas de vivienda y hábitat en las décadas del 60 y 70 en Argentina. Los aportes de John Turner y Víctor Pelli", ya citado

(c) Urbana: Rev. Eletrônica Cent. Interdiscip. Estud. Cid

Campinas (SP)

v.9, n.1 [15] p.01-14

ISSN 1982-0569 
población villera y de las diferentes ideologías urbanas y políticas de los profesionales actuantes en las agencias estatales encargadas del diseño de políticas habitacionales, muchos de los cuales tenían una pertenencia y una militancia política que difería del aparato estatal al que pertenecían. Estas negociaciones, luchas y procesos de avasallamiento, avance y retroceso estatal, fueron diferentes en los distintos contextos latinoamericanos. Las investigaciones enfocadas en el rol del estado como sujeto histórico y de sus agencias, no siempre homogéneas en sus concepciones, permiten adentrarnos en las fronteras sociales y materiales establecidas entre las urbanizaciones informales y el resto de la ciudad. Fronteras móviles, más permeables o más rígidas, en los diferentes contextos históricos y nacionales.

Los artículos aquí reunidos abordan las cuestiones planteadas a través de una gran diversidad de fuentes y metodologías de análisis. Una parte de ellos, toma como material de análisis la experiencia de los habitantes, que refiere directa o indirectamente a preguntas identitarias, es decir, quién es el sujeto de la experiencia desde el punto de vista social, cultural, político, de género, etcétera. El análisis de la experiencia implica, paralelamente, una toma de posición del investigador, que elige algunos aspectos identitarios por sobre otros. En este sentido, los trabajos que analizan la experiencia de los habitantes abren una gran diversidad de facetas de análisis. Si para autores como David Harvey la experiencia está condicionada por la identidad de clase, los artículos que integran el Dossier abren ventanas hacia otros aspectos identitarios, como las identidades ligadas al mundo del trabajo y las experiencias de lucha sindical, las identidades nacionales, de género, religiosas y también, el papel de las identidades políticas vinculadas, en algunos casos, a la lucha armada. Si el análisis de las prácticas permite acceder a la representación del mundo social de los individuos, también, a la luz de las investigaciones empíricas, la experiencia aparece como un proceso de construcción y deconstrucción de la vida de los individuos. Estos trabajos tienen el interés de reabrir la pregunta acerca del valor del análisis de la experiencia, desde el punto de vista historiográfico, entendiendo a la misma como representación del universo social de los sujetos y como agente de configuración de identidades individuales y colectivas.

Las diversas investigaciones reunidas en este Dossier se inscriben en las líneas de indagación de las cuales este artículo introductorio ha trazado un boceto. La mayor parte de los artículos explora las dinámicas sociales y sus conflictos en su dimensión urbana y territorial, nutriendo una línea de los estudios urbanos promisoria y fructífera, pues la dimensión de la espacialidad ha estado ausente en buena parte de los estudios pioneros sobre las urbanizaciones irregulares. En tal sentido, el trabajo de Adriana Laura Massidda aborda las disputas y negociaciones por el espacio urbano entre el estado y los habitantes de las villas La Lonja, Cildáñez y Castañares, en la Ciudad de Buenos Aires, desde una perspectiva que identifica diversas dinámicas que tensionan la apropiación del espacio, por la cual los habitantes de esas urbanizaciones debieron recurrir a diferentes mecanismos a lo largo del periodo enfocado. 
Las organizaciones villeras, sus identidades políticas y la relación con el estado, en la Argentina, están en el centro de los trabajos de Eva Camelli y de Manuela Luz Alvarez. Estas miradas resultan imprescindibles a la hora de observar las acciones estatales dirigidas hacia estos espacios urbanos y el componente identitario peronista, que ha caracterizado a buena parte de la dirigencia villera argentina. El grado de autonomía y los conflictos de esos dirigentes para sostener posiciones diferentes a las del gobierno peronista inaugurado en 1974 están en el centro del trabajo de Álvarez.

Por su parte, Erika Angélica Alcántar García \& Héctor Quiroz Rothe realizan un aporte a la construcción de una historiografía que tiene su objeto en el análisis de la emergencia y el proceso de conformación del tejido socioespacial de las ciudades mexicanas contemporáneas. Su trabajo se apoya en los resultados de una investigación documental y en trabajo de campo realizado por los autores como integrantes del Seminario de Historia del Urbanismo Popular del Posgrado en Urbanismo de la Universidad Nacional Autónoma de México.

También sobre los asentamientos informales de México, el trabajo de Milton Montehano Castillo analiza un caso de estudio, la llamada Ciudad Nezahualcóyotl, una urbanización de origen informal de más de un millón de habitantes y más de cincuenta años de conformación, lo que permite al autor identificar algunos elementos de diferenciación social dentro de la urbanización y el establecimiento no solo de pautas sociales de diferenciación, sino también de sectorización en el espacio urbano, en base a criterios de antigüedad de la población residente.

Retomando el tema de la segregación social y el establecimiento de fronteras sociales, el artículo de María José Bolaña sobre la construcción del discurso público acerca del cantegril montevideano, contribuye a la comprensión del modo en que las políticas gubernamentales delimitan sujetos en la ciudad, ubicándolos en el espacio simbólico y material, y delineando sus características desde determinados modelos urbanos y sociales.

Luciana Vaccotti, por su parte, ha trabajado la condición de los migrantes en las villas a través de la bibliografía sobre informalidad urbana y procesos migratorios, así como el modo en que esos discursos han construido históricamente la categoría "migrante" en tanto problema sociológico. Su artículo revisita la producción académica sobre el tema, orientada a rescatar las disputas e interacciones entre colectivos migrantes y locales, en situaciones de conflictividad social, en las cuales muchas veces los derechos de los primeros se ven vulnerados.

El recorte del colectivo inmigrante, en este caso proveniente de un país limítrofe, aparece como una de las facetas del trabajo de Leandro Daich Varela. Su artículo enfoca el caso de la Villa 31 de Retiro, la urbanización irregular de más larga data que pervive en Buenos Aires, dando cuenta del proceso de creación de cooperativas de autoconstrucción de nuevas viviendas en la periferia urbana como estrategia frente a la erradicación. Su estudio de caso es la organización de la Cooperativa Copacabana, creada durante la última dictadura militar argentina (1976-1983). A su vez, el trabajo explora las estrategias, ideas y conflictos al interior de la 
Cooperativa, y entre ésta y las autoridades, así como las relaciones de este grupo con la Iglesia Católica y con el Movimiento de Sacerdotes para el Tercer Mundo.

También el trabajo de las investigadoras brasileras Jimena Alejandra Veja y María Cristina da Silva Schicchi está enfocado en las erradicaciones que puso en práctica la última dictadura militar argentina. Su caso de estudio son las villas del Bajo Belgrano y de Colegiales, ambas en la Ciudad de Buenos Aires. Su artículo presenta un análisis de las estrategias y prácticas urbanísticas y su traducción en el espacio material de la ciudad, con el fin de convertirla en una "ciudad blanca", metáfora a que apelan las autoras en referencia a una ciudad moderna y socialmente homogénea.

Por su parte, el trabajo de Valeria Snitcofsky revisita críticamente las primeras interpretaciones producidas por Jose Luis Romero y por Gino Germani, desde los campos de la historia y de la sociología, respectivamente, para analizar de modo conjunto estos dos enfoques clásicos. Su trabajo revisa las herencias actuales de las perspectivas tradicionales que, aun cuando fueron criticadas en profundidad por una rica producción historiográfica desarrollada a lo largo de las últimas décadas, permanecen vigentes.

Finalmente, la investigación de Camila Chiara, María Mercedes Di Virgilio y Florencia Aramburu sobre la aplicación de una política pública reciente, los Planes Federales de Vivienda en el Área Metropolitana de Buenos Aires, reflexiona sobre las políticas habitacionales en el Conurbano Bonaerense. El análisis está elaborado a partir de una desagregación de datos y características de los mencionados Planes Federales en los diferentes municipios, buscando iluminar las diferencias en la aplicación local de este programa que si bien tuvo alcance federal, fue de implementación por cada uno de los cuarenta municipios que integran el Área Metropolitana

Los diferentes artículos que integran este Dossier despliegan, pues, diferentes miradas, estrategias metodológicas y enfocan diferentes objetos de análisis que encuentran un punto de convergencia en la cuestión habitacional de las villas miseria, favelas, cantegriles, callampas y asentamientos, como objeto de estudio científico de las ciudades latinoamericanas. Desde el punto de vista de la economía urbana y de las disputas por la inclusión y el derecho a la ciudad, los trabajos reunidos en este Dossier arrojan luz sobre la ciudad en tanto escenario de conflictos, entre intereses de agentes posicionados de manera diferencial, según su capital social, cultural y político, dentro de la escena urbana.

Dado que la ciudad puede considerarse como materialización de un excedente de producción y, por lo tanto, su control y apropiación son susceptibles de permanentes disputas, las urbanizaciones informales expresan estas tensiones con especial intensidad, debido a su vulnerabilidad social y jurídica. El objetivo de este Dossier es el de analizar y poner en discusión una serie de trabajos de investigación recientes, que renuevan este campo historiográfico, dando cuenta del despliegue político, social y territorial de estas disputas, en el largo plazo. 


\section{BIBLIOGRAFÍA CITADA}

ABOY, Rosa, "Arquitecturas de la vida doméstica. Familia y vivienda en Buenos Aires, 19141960". Anuario IEHS, número 23, pp. 355- 384. ISSN 0326-9671. Tandil, 2008

ABOY, Rosa, "Ellos y nosotros. Fronteras sociales en los años del primer peronismo". En Nuevo Mundo Mundos Nuevos, Revista electrónica editada por L'Ecole des Hautes Etudes en Sciences Sociales. Marzo, N. ${ }^{\circ}$ 8, ISSN 1626-0252. 2008.

ABOY, Rosa, Viviendas para el Pueblo. Espacio urbano y sociabilidad en el Barrio Los Perales, 1946- 1955. Buenos Aires: Fondo de Cultura Económica- UdeSA, 2005

BALLENT, Anahí, Las huellas de la política. Vivienda, ciudad, peronismo en Buenos. Aires, 19431955. Buenos Aires: Universidad de Quilmes, 2005

BARRIOS, Romina, "El Plan de Realojamiento de la Villa 7 en Mataderos, en Ciudad de Buenos Aires, entre 1971 y 1975". Tesis de Maestría en Administración Pública. Buenos Aires: Facultad de Ciencias Económicas, Universidad de Buenos Aires, 2012.

BARRIOS, Romina, "Entre la incapacidad de acción y la autonomía. Miradas sobre la participación popular en políticas de vivienda y hábitat en las décadas del 60 y 70 en argentina. Los aportes de John Turner y Víctor Pelli". Cuaderno Urbano núm. 16; junio 2014. issn 1853 - 3655

BLAUSTEIN, Eduardo, Prohibido vivir aquí: la erradicación de villas durante la dictadura. Buenos Aires: Punto de Encuentro, 2006.

BONDUKI, Nabil, Origens da habitacao social no Brasil, San Pablo: Estacao Liberdade, 2011

COSSE, Isabella, Pareja, sexualidad y familia en los años sesenta: una revolución discreta. Buenos Aires. Siglo XXI, 2010.

CRAVINO, María Cristina, Entre el arraigo y el desalojo. La Villa 31 de Retiro. Derecho a la ciudad, capital inmobiliario y gestión urbana, Buenos Aires: Universidad Nacional de General Sarmiento, 2009

CRAVINO, María Cristina, Vivir en la villa. Relatos, trayectorias y estrategias habitacionales, Buenos Aires: Universidad Nacional de General Sarmiento, 2009.

DAICH VARELA, Leandro, "Demandantes, autoconstructores y técnicos. Formas de resistencia en las villas de la Ciudad de Buenos Aires frente a las erradicaciones de la última dictadura militar". Quid 16 N6, 88-120. 2016

DAICH VARELA, Leandro, "El barrio La Asunción, relocalización de villas y autoconstrucción cooperativa en el ex municipio de General Sarmiento". Tesis de Doctorado en curso

DAICH VARELA, Leandro,; "Imágenes de la Cooperativa Copacabana. Un análisis sobre la erradicación de villas y la construcción de viviendas durante la última dictadura a partir de sus fotografías". Clepsidra. Revista Interdisciplinaria de Estudios sobre Memoria No9, (en prensa).

FERNÁNDEZ WAGNER, Raúl, "La construcción y deconstrucción histórica de lo social en el acceso a los bienes y servicios del hábitat". En Boletín del Instituto de la Vivienda. Mayo, Vol. 10, Núm. 50, Universidad de Chile, Santiago de Chile, 2004

GERMANI, Gino, "Investigación sobre los efectos sociales de la urbanización en un área obrera del Gran Buenos Aires", en Hauser, Philipe (editor), La urbanización en América Latina, Buenos Aires: Unesco, 1961 
GERMANI, Gino, Política y sociedad en una época de transición. De la sociedad tradicional a la sociedad de masas. Buenos Aires: Paidós, 1962. J. L. Romero, Latinoamérica, las ciudades y las ideas. Buenos Aires: Siglo XXI, 1976.

KOURY, Ana Paula y BONDUKI, Nabil, Os pioneiros da habitacao social. Cem anos de política pública no Brasil, San Pablo: UNESP, 2012

MÍGUEZ, Eduardo, "Familias de clase media: la formación de un modelo". En Devoto, F y Madero, M. Historia de la vida privada en Argentina. La Argentina plural (1870-1930). Buenos Aires. Taurus, 1999.

PARKER, David S. \& CASTILLO, Gabriela, "Laws in Translation: Asymmetric Globality and the Dialogue between French Expert Knowledge and Chilean Social Legislation, 1889-1931", Queen's University, 2017 (Inédito)

SNITCOFSKY, Valeria 'Villas de Buenos Aires: historia, experiencia y prácticas reivindicativas de sus habitantes (1958-1983) ". Tesis de Doctorado en Historia. Universidad de Buenos Aires, 2015.

TURNER, John, Housing by people. Londres: Marion Boyars, 1976.

TURNER, John, Libertad para construir. Mexico: Siglo XXI Editores, 1972. 